\title{
Effects of Cinnamaldehyde, Ocimene, Camphene, Curcumin and Farnesene on Candida albicans
}

\author{
Archana D. Thakre1, Shradha V. Mulange1, Santosh S. Kodgire', Gajanan B. Zore ${ }^{1,2}$, \\ S. Mohan Karuppayil ${ }^{1^{*}}$ \\ ${ }^{1}$ School of Life Sciences, Swami Ramanand Teerth Marathwada University, Nanded, India \\ ${ }^{2}$ Department of Crops and Soil Sciences, Washington State University, Pullman, USA \\ Email: *prof.karuppayil@gmail.com, *zoreg1@yahoo.co.in
}

Received 28 March 2016; accepted 31 July 2016; published 3 August 2016

Copyright (C) 2016 by authors and Scientific Research Publishing Inc.

This work is licensed under the Creative Commons Attribution International License (CC BY).

http://creativecommons.org/licenses/by/4.0/

c) (i) Open Access

\begin{abstract}
Efficacy of five plant molecules against thirty three clinical isolates and two standard strains of $C$. albicans, differentially susceptible to fluconazole (FLC) is tested in this study. Effect on biofilm (adhesion, development and maturation) formation, morphogenesis and synergy with fluconazole (FLC) against a FLC resistant strain of Candida albicans ATCC 10231 is also evaluated. All the plant molecules tested were equally effective against isolates and strains of $C$. albicans $(\mathrm{N}=35)$ tested in this study. Cinnamaldehyde was found most effective against planktonic growth followed by ocimene. Both the molecules exhibited fungicidal activity and killed $99.9 \%$ of inoculum within 80 and $20 \mathrm{~min}$ of exposure respectively at $0.62 \mathrm{mM}$ and $176.8 \mathrm{mM}$ concentrations. Curcumin (5 - $20 \mathrm{mM})$, camphene ( 8 - $32 \mathrm{mM}$ ) and farnesene (25 - $100 \mathrm{mM})$, although inhibited planktonic growth, were fungistatic. All the five plant molecules tested in this study inhibited morphogenesis significantly and exhibited considerable activity against biofilm formation. Inhibition of biofilm was found to be stage specific i.e. efficacy was more against adhesion followed by developing and mature biofilm. Plant molecules tested exhibited excellent synergy with fluconazole. However FIC index values $0.155,0.062$ and 0.046 indicate that ocimene was the most effective synergistic molecule inhibited planktonic growth, developing biofilm and mature biofilm growth respectively at very low concentrations. This is the first report of anti-Candida activity of three terpenoids viz. ocimene, farnesene and camphene against planktonic \& biofilm growth, morphogenesis as well as synergy with FLC. Plant molecules tested in this study may find use in antifungal chemotherapy individually and or in a combination with FLC.
\end{abstract}

\section{Keywords}

Ocimene, Farnesene, Camphene, Synergy, Candida albicans, Biofilm, Morphogenesis

\footnotetext{
${ }^{*}$ Corresponding author.
}

How to cite this paper: Thakre, A.D., Mulange, S.V., Kodgire, S.S., Zore, G.B. and Karuppayil, S.M. (2016) Effects of Cinnamaldehyde, Ocimene, Camphene, Curcumin and Farnesene on Candida albicans. Advances in Microbiology, 6, 627-643. 


\section{Introduction}

Fungal pathogens are infecting billions of people every year and deaths due to fungal infections are almost equal to that of Tuberculosis, Malaria etc. [1] [2]. Candida albicans is one of the most important opportunistic fungal pathogens responsible for superficial mucocutaneous infections of non-genital (Oropharyngeal) and genital (VVC, balanitis and balanoposthitis and candiduria) tracts of healthy individuals to life threatening, invasive infections in immunocompromised patients [1]-[3]. Oral candidiasis may be of pseudomembranous, hyperplastic, erythematous, angular cheilitis and Denture stomatitis type [2] [3]. It was also reported to be associated with caries in children and dental loss [1]-[3]. It is one of the most frequent agent associated with almost $80 \%$ of total fungal bloodstream infections commonly called as candidemia and fourth most common agents associated with nosocomial bloodstream infections with about 40\% attributable mortality [2]-[5]. Candidemia leads to colonization of intravascular medical devices like catheters, heart valve, pacemakers etc., in addition to denture in the form of biofilm, a highly complex micro-ecosystem extremely resistant to antifungal agents [2]-[5]. Dramatic increase in incidences of $C$. albicans infections in recent years is associated with the factors like prolonged dosage of broad-spectrum antibiotics, immunosuppressive therapy, extended stay at ICU and patients with AIDs, burns, surgery as well as malignancy etc., that affects either balance in body microflora and or paralyze host immune system [1]-[3] [5].

C. albicans is a polymorphic yeast which can exist in various morphological forms that facilitate its survival under extreme microenvironments by forming biofilms or invading and destructing target tissues [1] [2] [6]. Unlike other pathogenic organisms, morphogenic plasticity helps $C$. albicans in evading host immune responses and confers differential responses towards antifungal agents [1] [2] [6]. Being eukaryotic organisms, fungal specific drug targets are very few and thus limited numbers of antifungal agents like azoles, polyenes, allylamines, and echinocandins etc., are available in the market [7]. Among these, azoles and polyenes were the most promising ones but emergence of azole resistance among the $C$. albicans isolates and severe toxicities of polyenes in hosts has limited their use especially in difficult-to-treat infections like biofilms and invasive candidaisis [8] [9]. This situation has compelled scientific community to expedite the search for novel, potent and host friendly antifungal agents as well as look for alternative options like combination antifungal therapy [7]-[10]. Combination therapy is already successful and being used against several diseases [10]-[12].

Cinnamaldehyde, ocimene, farnesene, curcumin and camphene were tested in this study as earlier studies have shown that essential oils rich in these molecules (except curcumin) exhibits excellent anti-Candida activity [13]-[19]. Curcumin was included to evaluate its potential against biofilm formation as it was reported to inhibit morphogenesis in C. albicans as well as shown excellent apoptosis inducing activity [20]. We have tested efficacy of these plant molecules against planktonic growth, morphogenesis and biofilm formation (adhesion, development and maturation) of C. albicans. Synergistic potential with FLC against planktonic and biofilm growth of C. albicans is also evaluated in this study.

\section{Materials and Methods}

\subsection{Plant Molecules and Growth Media}

Plant molecules viz. ocimene ( $\geq 90 \% \mathrm{v} / \mathrm{v})$, cinnamaldehyde $(\geq 95 \% \mathrm{v} / \mathrm{v})$, farnesene ( $\geq 90 \% \mathrm{v} / \mathrm{v})$, curcumin and camphene were purchased from Sigma-Aldrich India Pvt. Ltd., Bangalore (India).

Yeast Extract Peptone Dextrose broth, RPMI 1640 medium, Horse Serum and MTT were purchased from Hi-media Laboratories, Pvt. Ltd. Mumbai (India). Polystyrene make 96 well micro titer plates were procured from Tarson India Ltd.

\subsection{Candida albicans Isolates and Strains}

Thirty-three clinical isolates of Candia albicans, differentially susceptible to fluconazole (FLC) (Resistant $-\mathrm{N}=$ $11, \mathrm{~S}-\mathrm{DD}-\mathrm{N}=02$ and susceptible $-\mathrm{N}=22$ ) used in this study were received from Swami Ramanand Teerth Culture Collection (SRTCC) of School of Life Sciences, Swami Ramanand Teerth Marathwada University, Nanded (MS) India. Out of thirty-three, 22 isolates were from oral candidiasis (15 from HIV positive and seven from healthy individuals), 6 from respiratory, 3 from genitourinary and 2 from gastroenteritis infections. A FLC resistant strain of C. albicans ATCC 10231 (Member of CaDR MP-8 Panel developed by ATCC for drug testing) [28] and a susceptible strain ATCC 90028 were procured from the Microbial Type Culture Collection, Institute 
of Microbial Technology (IMTECH), Chandigarh (India) and included as a quality control in this study. All the cultures were maintained on yeast extract peptone dextrose (YPD) agar slants at $4^{\circ} \mathrm{C}$.

\subsection{Preparation of Working Stocks of Plant Molecules}

Concentrations of ocimene, cinnamaldehyde, and farnesene procured in liquid form were found to be 5.824, 7.545 and 3.580 molar, respectively. Considering the solubility issues, $10 \%$ (v/v) ethanol was added to ocimene and farnesene to improve the solubility. Cinnamaldehyde was needed in very less concentration and thus diluted with ethanol by two fold. Stock solution of camphene $(1 \mathrm{M})$ was prepared in ethanol. Curcumin stock solution $(1 \mathrm{M})$ was prepared by solubilizing in minimum volume of $0.5 \mathrm{M} \mathrm{NaOH}$ and diluting immediately with YPD.

\subsection{Inhibition of Planktonic Growth of Candida albicans}

Anti-Candida activity of five plant molecules against thirty-three clinical isolates and two standard strains of $C$. albicans was tested by broth micro dilution assay (CLSI M27-A3) as mentioned previously [14] [15] [29]. Briefly, $100 \mu \mathrm{L}$ YPD broth containing $24 \mathrm{~h}$ grown C. albicans yeast phase cells $\left(2 \times 10^{3} \mathrm{cfu} / \mathrm{mL}\right)$ and $0.001 \%$ (v/v) tween 20 was transferred aseptically to each well of the 96 well micro titer plate. However double volume $(200 \mu \mathrm{L})$ was added in the 12th well of each row, highest concentration of plant molecules were added to this well and serially diluted up to 8 fold. Well number 3 and 2 of each row served as respective solvent controls and well number 1 as control without solvent. Doubling dilutions of plant molecules used were as follows: ocimene (352 to $1.37 \mathrm{mM}$ ), cinnamaldehyde (5 to $0.019 \mathrm{mM}$ ), farnesene (300 to $1.17 \mathrm{mM}$ ), curcumin (20 to $0.078 \mathrm{mM}$ ) and camphene (32 to $0.125 \mathrm{mM}$ ). Plates were observed visibly after $24 \mathrm{~h}$ of incubation at $35^{\circ} \mathrm{C}$ and concentrations causing complete growth inhibition were considered as minimum inhibitory concentration (MIC). Triplicates were used for each concentration and experiment was repeated thrice.

Minimum fungicidal concentrations (MFCs) of plant molecules were determined by plating $5 \mu \mathrm{l}$ culture from these wells on YPD agar plates. Number of colonies appeared on the agar plates after $48 \mathrm{~h}$ of incubation at $35^{\circ} \mathrm{C}$ were counted. Lowest concentration killing of 99.9\% inoculums was considered as MFCs [14] [15].

\subsection{Time Kill Assay}

Time dependant killing of a Fluconazole resistant strain of C. albicans ATCC10231 inoculum by MFCs of ocimene and cinnamaldehyde was studied as done previously by Zore et al. [14] [15]. In brief, C. albicans cells $\left(2.5 \times 10^{3} \mathrm{cfu} / \mathrm{ml}\right)$ in $100 \mu \mathrm{l}$ YPD broth, were exposed to MFCs of ocimene and cinnamaldehyde for different time intervals viz. 0, 5, 10, 20, 40, $80 \mathrm{~min}$. After different time intervals, cells were washed twice, re-suspended in $50 \mu \mathrm{l}$ of YPD broth and inoculated on YPD agar plates. Number of colonies appeared on these plates were counted after incubation at $30^{\circ} \mathrm{C}$ for $48 \mathrm{~h}$ and compared with that of the control. Wells lacking plant molecule but containing respective solvent (ethanol) were served as growth controls. Triplicates were used for each time interval and experiment was repeated thrice.

\subsection{Inhibition of Morphogenesis in Candida albicans (ATCC 10231)}

Effect of all the five plant molecules on serum induced morphogenesis of C. albicans (ATCC 10231) was studied by using micro titer plate based morphological assay as done previously by Zore et al. [14] [15]. In brief, $100 \mu \mathrm{l}$ of YPD supplemented with $25 \%$ horse serum and 24 h grown C. albicans yeast phase cells $\left(10^{5} \mathrm{cfu} / \mathrm{ml}\right)$, were treated with different concentrations of plant molecules viz. ocimene (176 to $1.37 \mathrm{mM}$ ), cinnamaldehyde ( 5 to $0.031 \mathrm{mM}$ ), farnesene (100 to $0.78 \mathrm{mM}$ ), curcumin (20 to $0.15 \mathrm{mM}$ ) and camphene (16 to $0.12 \mathrm{mM})$. Three wells were used for each concentration and wells lacking plant molecule but containing respective solvents were used as control. Plates were incubated at $37^{\circ} \mathrm{C}$ for 90 minutes, cells of different morphological types (Budded, un-budded, hyphae and pseudohyphae) were counted after incubation microscopically using hemocytometer and percentage inhibition of hyphae induction was calculated (Figure 2).

\subsection{Inhibition of Biofilm (Adhesion, Development and Maturation) Formation}

\subsubsection{Inoculum Preparation}

C. albicans cells grown in YPD for $24 \mathrm{~h}$ at $30^{\circ} \mathrm{C}$ were harvested, washed with sterile distilled water and re-suspended in phosphate buffered saline (PBS). Cell density was adjusted to $1 \times 10^{7} / \mathrm{ml}$, aseptically. 


\subsubsection{Biofilm Assay}

Effect of plant molecules viz. ocimene (352 to $23.1 \mathrm{mM}$ ), cinnamaldehyde (5 to $0.312 \mathrm{mM}$ ), farnesene (300 to $18.52 \mathrm{mM}$ ), curcumin (20 to $7.5 \mathrm{mM}$ ) and camphene (32 to $3 \mathrm{mM}$ ) was evaluated by measuring adhesion (90 min), development $(24 \mathrm{~h})$ and maturation $(48 \mathrm{~h})$ of $C$. albicans (ATCC 10231) biofilms by MTT assay after removing non adhered cells [4] [27].

In brief, adhesion was performed by dispensing $100 \mu \mathrm{l}$ inoculum without and with plant molecules (concentrations mentioned above) aseptically to the wells and incubated at $37^{\circ} \mathrm{C}$ for $90 \mathrm{~min}$. Non adhered cells were removed by washing the wells thrice with PBS and adhesion was measured and compared with the respective solvent controls. To test efficacy against biofilm development, cells were allowed to adhere (adhesion) as mentioned above. $100 \mu \mathrm{l}$ of fresh RPMI 1640 medium with and without plant molecules were added to these wells and incubated further. Growth was measured after $24 \mathrm{~h}$ incubation at $37^{\circ} \mathrm{C}$ and compared with respective solvent controls. To test effect against mature biofilm, $24 \mathrm{~h}$ old biofilms developed as mentioned above were used. 100 $\mu \mathrm{l}$ of fresh RPMI 1640 medium with and without plant molecules were added to these wells with developed biofilms after removing non adhered cells and incubated further at $37^{\circ} \mathrm{C}$. Growth was measured after $48 \mathrm{~h}$ incubation and compared with respective solvent controls. Triplicates were used for each concentration and experiment was repeated three times. MTT assay was performed as described previously [27].

\subsubsection{Synergistic Activity of Plant Molecules and Fluconazole against Planktonic and Biofilm Growth (Development and Maturation) of a FLC Resistant Strain of Candida albicans (ATCC 10231)}

Effect of plant molecules on fluconazole susceptibility in planktonically growing C. albicans (ATCC 10231) was studied by micro dilution checkerboard assay [21]-[30]. Concentration of plant molecules used with FLC (2 to $128 \mathrm{~g} / \mathrm{ml})$ were as follows: ocimene $(88-5.5 \mathrm{mM})$, cinnamaldehyde $(0.625-0.037 \mathrm{mM})$, farnesene $(100$ $6.25 \mathrm{mM})$, curcumin $(20-1.25 \mathrm{mM})$ and camphene $(16-1 \mathrm{mM})$. Similarly synergistic activity of FLC ( $\geq 256-8$ $\mathrm{g} / \mathrm{ml}$ ) with ocimene (22 to $5.5 \mathrm{mM})$, cinnamaldehyde (0.31 - 0.07), farnesene (18.7 - $4.65 \mathrm{mM})$, curcumin (3.75 $0.93 \mathrm{mM}$ ) and camphene (3-0.75 mM) was evaluated against development and maturation of C. albicans biofilms. Biofilm development and maturation was performed as mentioned above (biofilm assay). Fractional inhibitory concentrations (FICs) and FIC index values were calculated for each plant molecules [27] [30]. FIC is inhibitory concentration in combinations divided by the concentration that has same effect when used individually while FIC index values are sum of the FICs [26]. FIC index ( $\sum$ FIC) shows type of interaction between two compounds viz. value 0.5 to 4.0 shows additive interaction, value $<0.5$ exhibit synergistic interaction and value $>$ 4.0 exhibit antagonistic interactions [4] [26] [27] [30].

\section{Results}

\subsection{Inhibition of Planktonic Growth}

All the five plant molecules tested, inhibited planktonic growth and were equally effective against FLC resistant as well as susceptible isolates of C. albicans (Table 1). C. albicans (ATCC 10231) is a FLC resistant strain (MIC is $>128 \mu \mathrm{g} / \mathrm{ml}$ ) used as a FLC resistant member in a C. albicans Drug resistant Panel MP-8 developed by ATCC for drug testing (CaDR MP-8 Panel, ATCC). In our study, MIC of FLC for planktonic growth could not be achieved up to $128 \mu \mathrm{g} / \mathrm{ml}$ and thus MIC is denoted as $>128 \mu \mathrm{g} / \mathrm{ml}$.

Cinnamaldehyde was found to be most effective, inhibited all the isolates at or less than $0.62 \mathrm{mM}$ concentration (Table 1). MICs of remaining four molecules were ranged from 5 - $20 \mathrm{mM}$ (curcumin), 8 - $32 \mathrm{mM}$ (camphene), 25 - 100 (farnesene) and 44.1 - 176.4 (ocimene) (Table 1). Cinnamaldehyde and ocimene exhibited fungicidal activity while remaining three were fungistatic (Table 1, Figure 1, Supplementary Figure 1(a), Figure 1(b)). In general, MFCs of cinnamaldehyde and ocimene were greater than MICs (Table 1, Supplementary Figure 1(a)). Time dependant kill curve analysis showed that MFCs of cinnamaldehyde $(0.62 \mathrm{mM})$ and ocimene (88.2 mM) kills 99.9\% inoculums within 80 and 20 minutes of exposure respectively (Table 1, Supplementary Figure 1(b)).

\subsection{Inhibition of Morphogenesis by Plant Molecules}

All the plant molecules tested exhibited excellent anti-morphogenic activity and inhibited hyphae as well as 
Table 1. Anti-Candida potential of plant molecules against clinical isolates $(\mathrm{N}=33)$ and standard strains of Candida albicans $(n=2)$.

\begin{tabular}{|c|c|c|c|c|c|}
\hline \multirow{2}{*}{ Assay } & \multirow{2}{*}{ Compounds } & \multirow{2}{*}{ MIC (mM) } & \multicolumn{3}{|c|}{ *Candida albicans strains and isolates $(\mathrm{N}=35)$} \\
\hline & & & Susceptible $(\mathrm{N}=21)$ & S-DD $(\mathrm{N}=2)$ & Resistant $(\mathrm{N}=12)$ \\
\hline & & 44.1 & $05(\mathbf{0})$ & - & 03 \\
\hline & Ocimene & 88.2 & $08(\mathbf{1 1})$ & 01 & $03(\mathbf{0 3})$ \\
\hline & & 176.4 & $08(\mathbf{1 0})$ & $01(\mathbf{0 2})$ & $06(\mathbf{0 9})$ \\
\hline & & 0.15 & $04(0)$ & - & 02 \\
\hline & Cinnamaldehyde & 0.31 & $04(07)$ & - & $03(\mathbf{0 1})$ \\
\hline & & 0.62 & $13(\mathbf{1 4})$ & $02(02)$ & 07 (11) \\
\hline & & 25 & 13 & - & 05 \\
\hline \multirow[t]{8}{*}{ Broth Micro Dilution Assay } & Farnesene & 50 & 02 & - & - \\
\hline & & 100 & 06 & 02 & 07 \\
\hline & & 05 & 06 & - & 02 \\
\hline & Curcumin & 10 & 05 & - & 04 \\
\hline & & 20 & 10 & 02 & 06 \\
\hline & & 8 & 08 & - & 05 \\
\hline & Camphene & 16 & 10 & - & 06 \\
\hline & & 32 & 03 & 02 & 01 \\
\hline
\end{tabular}

Bold values in parentheses indicate the number of isolates wherein 99.9\% inoculum was killed by respective concentration (MFC), S-DD, dosedependent susceptible to fluconazole, (According to CLSI M27 A3, 2007). All the compounds were tested in triplicates (for each concentrations) and assay was repeated three times.

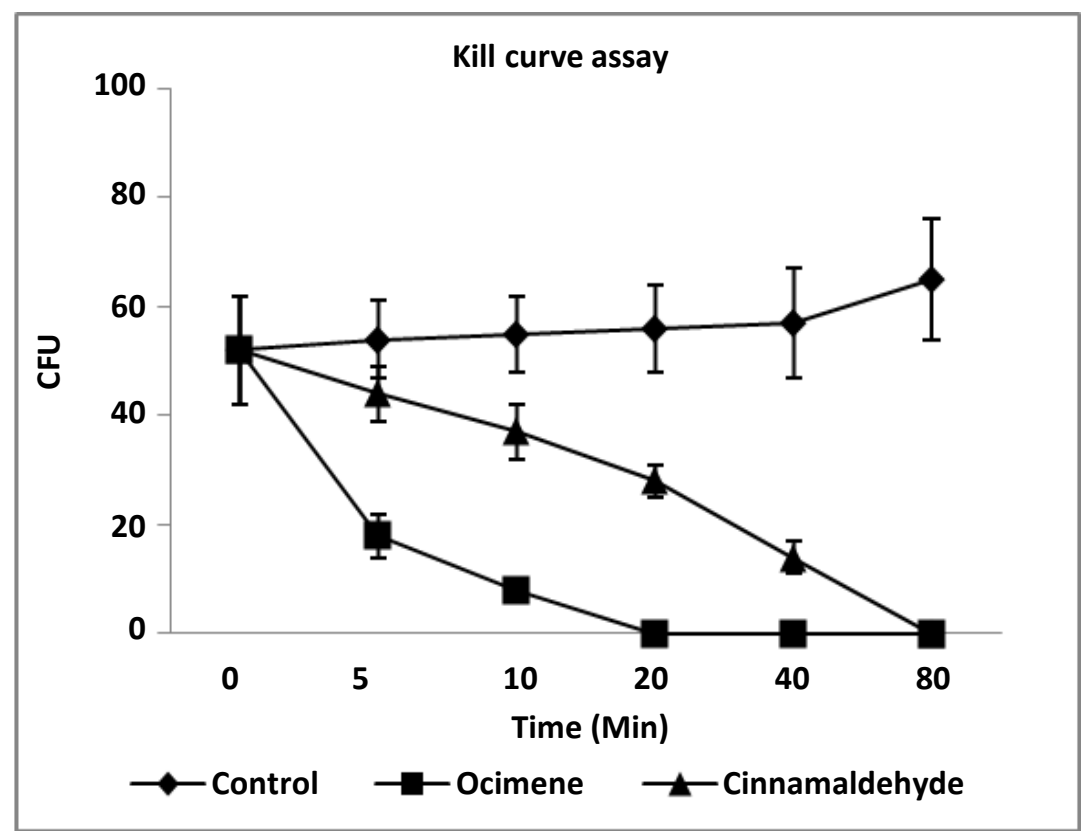

Figure 1. Time kill curve at MFCs of ocimene and cinnamaldehyde in Candida albicans (ATCC 10231). 
pseudohyphae formation completely at the MICs of growth (Figure 2). Compared to planktonic growth, hyphae formation seems to be more sensitive as $50 \%$ inhibition of morphogenesis was achieved at very low concentrations viz. $22 \mathrm{mM}$ (ocimene), $0.078 \mathrm{mM}$ (cinnamaldehyde), $9.1 \mathrm{mM}$ (farnesene), $1.25 \mathrm{mM}$ (curcumin) and $3 \mathrm{mM}$ (camphene) (Figure 2). Inhibition of hyphae formation by cinnamaldehyde, farnesene, curcumin and camphene lead to pseudohyphae formation initially but higher concentrations resulted in to un-budded cells (Figure 2).

\subsection{Inhibition of Biofilm Formation by Plant Molecules}

Biofilm assay (adhesion, development and maturation) showed that all the five plant molecules inhibit adhesion in a concentration dependent manner (Table 2, Supplementary Figures 1(c)-1(e)). Farnesene (300 mM) and ocimene (352 mM) inhibited adhesion completely while curcumin (60 $\mathrm{mM})$ and cinnamaldehyde $(5 \mathrm{mM})$ caused 97\% and 91\% inhibition respectively (Table 2, Supplementary Figures 1(c)-1(e)). Camphene was least effective, could inhibit adhesion by $64 \%$ at $48 \mathrm{mM}$ concentration (Table 2, Supplementary Figures 1(c)-1(e)).
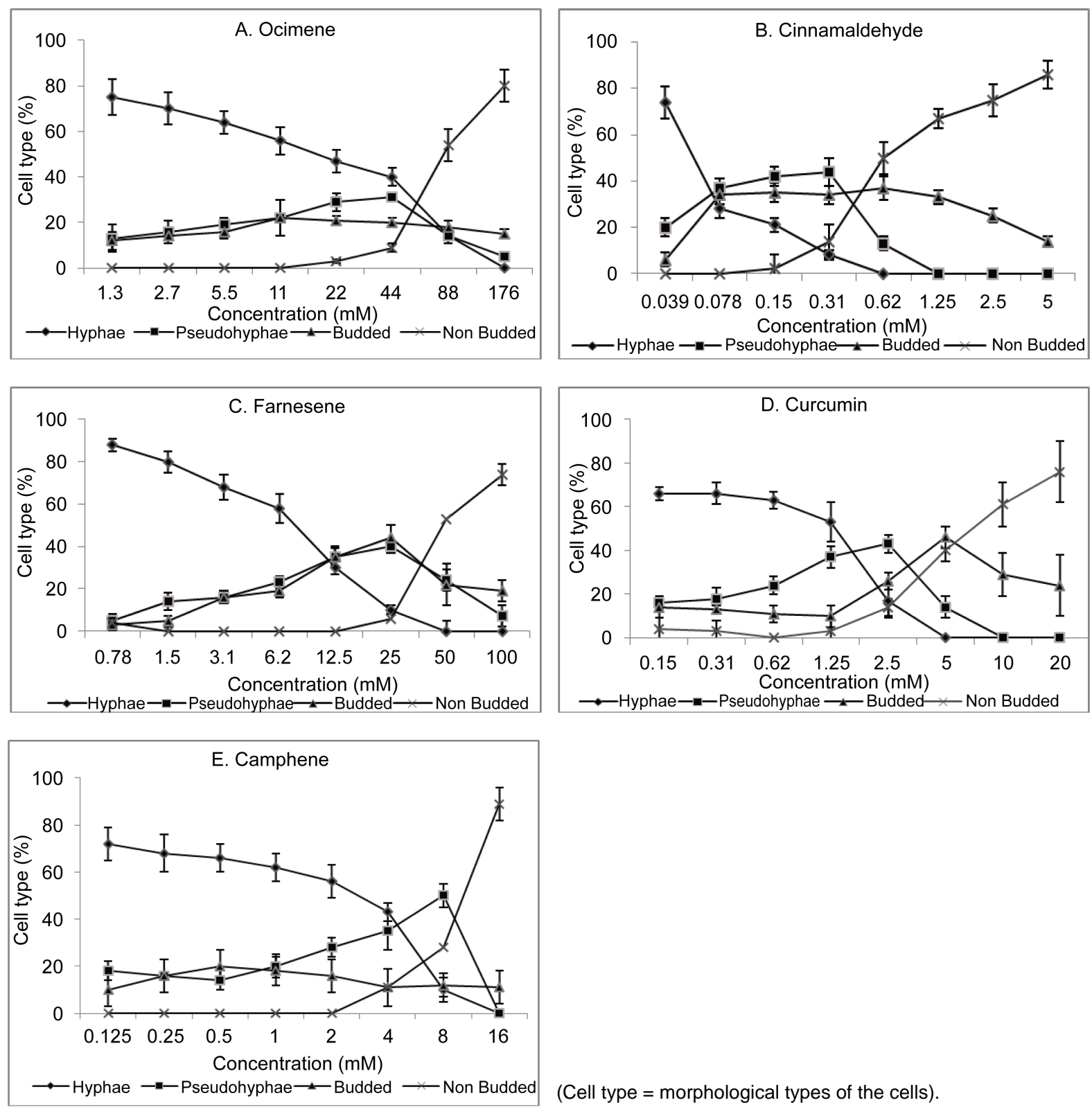

(Cell type $=$ morphological types of the cells).

Figure 2. Effect of Plant Molecules on Morphogenesis in Candida albicans (ATCC 10231). 
Table 2. Effect of Plant Molecules on Candida albicans biofilm progression: Adhesion, development and maturation.

\begin{tabular}{|c|c|c|c|c|c|c|}
\hline \multirow{3}{*}{$\begin{array}{c}\text { Plant molecules/Developmental Stage } \\
\text { Ocimene }\end{array}$} & \multicolumn{6}{|c|}{ Biofilm Formation (\%) } \\
\hline & \multicolumn{6}{|c|}{ Concentrations (mM) } \\
\hline & Control & 23.1 & 44.2 & 88.4 & 176.8 & 352 \\
\hline Adhesion & $100 \pm 0$ & $60 \pm 2$ & $5 \pm 1$ & $4 \pm 1$ & $4 \pm 0$ & $0 \pm 0$ \\
\hline Developing Biofilm & $100 \pm 0$ & $54 \pm 4.28$ & $27 \pm 10.24$ & $22 \pm 0.25$ & $18 \pm 0.64$ & $14 \pm 0.31$ \\
\hline Mature Biofilm & $100 \pm 0$ & $80 \pm 14.3$ & $69 \pm 7.12$ & $49 \pm 8.80$ & $41 \pm 5.12$ & $25 \pm 6.77$ \\
\hline Cinnamaldehyde & $\mathbf{0}$ & 0.312 & 0.625 & 1.25 & 2.5 & 5 \\
\hline Adhesion & $100 \pm 0$ & $100 \pm 0$ & $67 \pm 3$ & $26 \pm 7$ & $23 \pm 6$ & $21 \pm 1$ \\
\hline Developing Biofilm & $100 \pm 0$ & $25 \pm 19$ & $22 \pm 1.0$ & $20 \pm 0.4$ & $17 \pm 0.5$ & $13 \pm 0.6$ \\
\hline Mature Biofilm & $100 \pm 0$ & $40 \pm 5.6$ & $37 \pm 8$ & $36 \pm 7.61$ & $35 \pm 12.63$ & $35 \pm 14.9$ \\
\hline Farnesene & $\mathbf{0}$ & 18.52 & 37.5 & 75 & 150 & 300 \\
\hline Adhesion & $100 \pm 0$ & $70 \pm 2$ & $62 \pm 9$ & $5 \pm 2$ & $4 \pm 1$ & 0 \\
\hline Developing Biofilm & $100 \pm 0$ & $42 \pm 18$ & $34 \pm 16$ & $33 \pm 5.97$ & $30 \pm 4$ & $28 \pm 6$ \\
\hline Mature Biofilm & $100 \pm 0$ & $64 \pm 15$ & $50 \pm 7.94$ & $47 \pm 7.66$ & $33 \pm 1.77$ & $32 \pm 9.2$ \\
\hline Curcumin & $\mathbf{0}$ & 7.5 & 15 & 15 & 30 & 60 \\
\hline Adhesion & $100 \pm 0$ & $82 \pm 1$ & $61 \pm 5$ & $5 \pm 2$ & $4 \pm 2$ & $3 \pm 1$ \\
\hline Developing Biofilm & $100 \pm 0$ & $100 \pm 1.36$ & $100 \pm$ & $87 \pm 1.71$ & $39 \pm 5.1$ & $39 \pm 10.2$ \\
\hline Mature Biofilm & $100 \pm 0$ & $86 \pm 3.74$ & $82 \pm 0.75$ & $72 \pm 6.05$ & $65 \pm 0.82$ & $62 \pm 1.63$ \\
\hline Camphene & $\mathbf{0}$ & 3 & 6 & 12 & 24 & 48 \\
\hline Adhesion & $100 \pm 0$ & $75 \pm 1$ & $55 \pm 1$ & $41 \pm 1$ & $39 \pm 1$ & $36 \pm 1$ \\
\hline Developing Biofilm & $100 \pm 0$ & $48 \pm 23$ & $34 \pm 14$ & $18 \pm 5.33$ & $10 \pm 0.36$ & $9 \pm 0.97$ \\
\hline Mature Biofilm & $100 \pm 0$ & $80 \pm 8.11$ & $68 \pm 13$ & $65 \pm 12$ & $48 \pm 11.5$ & $30 \pm 3.3$ \\
\hline Fluconazole & $\mathbf{0}$ & 16 & 32 & 64 & 128 & 256 \\
\hline Developing Biofilm & $100 \pm 0$ & $52 \pm 5$ & $39 \pm 3$ & $38 \pm 4$ & $38 \pm 3$ & $38 \pm 3$ \\
\hline Mature Biofilm & $100 \pm 0$ & $62 \pm 14$ & $54 \pm 10$ & $46 \pm 14$ & $45 \pm 10$ & $45 \pm 11$ \\
\hline
\end{tabular}

Numbers represent biofilm (adhesion, developing and mature) growth\% \pm Standard deviation. * Stage of development $($ Duration): Adhesion $=0$ - 90 min, Developing biofilm $=90 \mathrm{~min}-24 \mathrm{~h}$, Mature biofilm $=24-48 \mathrm{~h}$.

All the five plant molecules inhibited developing biofilm considerably but could not achieve complete inhibition (Table 2, Supplementary Figures 1(c)-1(e)). Cinnamaldehyde (5 mM), camphene (48 mM), ocimene (352 $\mathrm{mM}$ ) and farnesene (300 $\mathrm{mM}$ ) inhibited biofilm development by $87 \%, 90 \%, 86 \%$ and $72 \%$ respectively (Table 2, Supplementary Figures 1(c)-1(e)). Curcumin caused $60 \%$ inhibition at $30 \mathrm{mM}$ but further increase in concentration could not increase inhibition significantly (Table 2, Supplementary Figures 1(c)-1(e)). $256 \mu \mathrm{g} / \mathrm{ml}$ concentration of FLC could cause 62\% inhibition of biofilm development (Table 2).

Mature biofilm seems to be more tolerant to plant molecules tested in this study as MIC of planktonic growth i.e. ocimene ( $88.4 \mathrm{mM})$, cinnamaldehyde $(0.31 \mathrm{mM})$ and farnesene $(37.5 \mathrm{mM})$ could inhibit mature biofilm by $50 \%$ (Table 2, Supplementary Figures 1(c)-1(e)). A maximum of 75, 65 and 68\% inhibition was observed by ocimene $(352 \mathrm{mM})$, cinnamaldehyde $(5 \mathrm{mM})$ and farnesene $(300 \mathrm{mM})$ respectively (Table 2, Supplementary Figures 1(c)-1(e)). Camphene (48 mM) and FLC (256 $\mu \mathrm{g} / \mathrm{ml})$ inhibited mature biofilm by $70 \%$ and $55 \%$ respectively while curcumin concentration up to $60 \mathrm{mM}$, could not achieve $50 \%$ inhibition (Table 2, Supplementary Figures 1(c)-1(e)).

\subsection{Synergistic Activity of Plant Molecules with FLC against Candida albicans ATCC 10231}

Plant molecules tested in this study showed very good synergistic activity against planktonic and biofilm 
(developing and mature) growth. As C. albicans (ATCC 10231) is a FLC resistant strain, $128 \mu \mathrm{g} / \mathrm{ml} \mathrm{FLC} \mathrm{could}$ not inhibit planktonic growth completely and thus MIC is considered as $>128 \mu \mathrm{g} / \mathrm{ml}$ in synergy assay (Table 3). Similarly, fluconazole $(256 \mu \mathrm{g} / \mathrm{ml})$ could inhibit developing biofilm by $62 \%$ and mature biofilm by $55 \%$ and thus concentration required for more inhibition ( $>62 \%$ and $>55 \%$ ) is considered as $>256 \mu \mathrm{g} / \mathrm{ml}$ in synergy assay (Table 3).

Table 3. Synergistic activity of plant molecules and fluconazole against A. Planktonic growth and B. Developing and C. Mature Biofilm of a FLC-resistant strain of Candida albicans (ATCC 10231).

\begin{tabular}{|c|c|c|c|c|c|c|}
\hline \multirow{2}{*}{ Combinations } & \multicolumn{2}{|c|}{ MIC } & \multicolumn{2}{|c|}{ FICs } & \multirow{2}{*}{ FIC index } & \multirow{2}{*}{ Interaction } \\
\hline & FLC $(\mu \mathrm{g} / \mathrm{ml})$ & Comp. (mM) & FLC & Comp. & & \\
\hline \multicolumn{7}{|c|}{ A. Planktonic Growth (MIC100) } \\
\hline FLC alone & $>128$ & 0 & 1 & 0 & 1 & NI \\
\hline Ocimene + FLC & 4 & 22 & 0.031 & 0.124 & 0.155 & synergistic \\
\hline Ocimene alone & 0 & 176.4 & 0 & 1 & 1 & NI \\
\hline Cinnamaldehyde + FLC & 4 & 0.15 & 0.031 & 0.241 & 0.273 & synergistic \\
\hline Cinnamaldehyde & 0 & 0.62 & 0 & 1 & 1 & NI \\
\hline Farnesene + FLC & 8 & 12.5 & 0.062 & 0.125 & 0.187 & synergistic \\
\hline Farnesene alone & 0 & 100 & 0 & 1 & 1 & NI \\
\hline Curcumin + FLC & 8 & 2.5 & 0.062 & 0.125 & 0.187 & synergistic \\
\hline Curcumin alone & 0 & 20 & 0 & 1 & 1 & NI \\
\hline Camphene + FLC & 8 & 4 & 0.064 & 0.25 & 0.289 & synergistic \\
\hline Camphene alone & 0 & 16 & 0 & 1 & 1 & NI \\
\hline \multicolumn{7}{|c|}{ B. Developing Biofilm (MIC90) } \\
\hline FLC alone & $>256$ & 0 & 1 & 0 & 1 & NI \\
\hline Cinnamaldehyde + FLC & 8 & 0.152 & 0.031 & 0.030 & 0.061 & Synergistic \\
\hline Cinnamaldehyde & 0 & 5 & 0 & 1 & 1 & NI \\
\hline Farnesene + FLC & 8 & 18.7 & 0.031 & 0.062 & 0.093 & Synergistic \\
\hline Farnesene & 0 & 300 & 0 & 1 & 1 & \\
\hline \multicolumn{7}{|c|}{ MIC80 } \\
\hline Ocimene + FLC & 8 & 5.5 & 0.031 & 0.031 & 0.062 & Synergistic \\
\hline Ocimene & 0 & 176.8 & 0 & 1 & 1 & NI \\
\hline Camphene + FLC & 8 & 1.5 & 0.031 & 0.125 & 0.156 & Synergistic \\
\hline Camphene & 0 & 12 & 0 & 1 & 1 & \\
\hline \multicolumn{7}{|c|}{ MIC70 } \\
\hline Curcumin + FLC & 8 & 1.85 & 0.031 & 0.030 & 0.062 & Synergistic \\
\hline Curcumin & 0 & 60 & 0 & 1 & 1 & NI \\
\hline \multicolumn{7}{|c|}{ C. Mature Biofilm (MIC 90) } \\
\hline FLC alone & $>256$ & 0 & 1 & 0 & 1 & NI \\
\hline Cinnamaldehyde + FLC & 8 & 0.152 & 0.031 & 0.030 & 0.061 & Synergistic \\
\hline Cinnamaldehyde & 0 & 5 & 0 & 1 & 1 & NI \\
\hline \multicolumn{7}{|c|}{ MIC80 } \\
\hline FLC alone & $>256$ & 0 & 1 & 0 & 1 & NI \\
\hline Ocimene + FLC & 8 & 5.5 & 0.031 & 0.015 & 0.046 & Synergistic \\
\hline Ocimene alone & 0 & 352 & 0 & 1 & 1 & NI \\
\hline \multicolumn{7}{|c|}{ MIC50 } \\
\hline FLC alone & 256 & 0 & 1 & 0 & 1 & NI \\
\hline Farnesene + FLC & 8 & 9.35 & 0.031 & 0.249 & 0.280 & Synergistic \\
\hline Farnesene & 0 & 37.5 & 0 & 1 & 1 & \\
\hline Camphene + FLC & 8 & 0.75 & 0.031 & 0.031 & 0.062 & Synergistic \\
\hline Camphene & 0 & 24 & 0 & 1 & 1 & NI \\
\hline
\end{tabular}

FICs $=$ fractional inhibitory concentrations, FIC index $=\Sigma$ FICs, FLC $=$ fluconazole, Comp. $=$ compounds tested. (FICI $\leq 0.5=$ Synergy, FICI $>0.5-\leq$ $4.0=$ No interaction and FICI $>4$ = Antagonistic; Odds 2003). FLC inhibited developing and mature biofilms by $62 \%$ and $55 \%$ respectively at 256 $\mu \mathrm{g} / \mathrm{ml}$ and thus MIC 90, 80 and 70 of FLC is considered as $>256 \mu \mathrm{g} / \mathrm{ml}$. Synergy assays were repeated three time. 
Plant molecules tested sensitized C. albicans cells and brought down MIC of FLC significantly (Table 3). Ocimene $(22 \mathrm{mM})$ and cinnamaldehyde $(0.15 \mathrm{mM})$ brought down MIC of FLC by 32 fold $>128 \mu \mathrm{g} / \mathrm{ml}$ to 4 $\mu \mathrm{g} / \mathrm{ml})$ while farnesene $(12.5 \mathrm{mM})$, curcumin $(2.5 \mathrm{mM})$ and camphene $(4 \mathrm{mM})$ lowered down MIC by 16 fold $(>128 \mu \mathrm{g} / \mathrm{ml}$ to $8 \mu \mathrm{g} / \mathrm{ml}$ ) (Table 3). FIC index value, 0.155 shows that ocimene is the most synergistic molecule followed by 0.187 (farnesene and curcumin), 0.273 (cinnamaldehyde) and 0.289 (camphene) (Table 3).

All the five plant molecules tested, inhibited both developing and mature biofilm significantly at very low concentrations (sub toxic) when used in combinations with FLC, indicating excellent synergistic potential (Table 3). Cinnamaldehyde $(0.152 \mathrm{mM})$ and farnesene $(18.7 \mathrm{mM})$ inhibited developing biofilm by $90 \%$; ocimene $(5.5 \mathrm{mM})$ and camphene $(1.5 \mathrm{mM})$ by $80 \%$ while curcumin $(1.85 \mathrm{mM})$ by $70 \%$ when used with FLC (8 $\mu \mathrm{g} / \mathrm{ml}$ ) (Table 3). FICI values indicate that cinnamaldehyde (0.061) exhibited more synergistic activity with FLC against developing biofilm followed by ocimene and curcumin (0.062), farnesene (0.093) and camphene (0.156) (Table 3).

Fluconazole $(8 \mu \mathrm{g} / \mathrm{ml})$ inhibited mature biofilm by $90 \%$ synergistically with cinnamaldehyde $(0.152 \mathrm{mM})$ while ocimene $(5.5 \mathrm{mM})$, farnesene $(9.7 \mathrm{mM})$ and camphene $(0.75 \mathrm{mM})$ could cause $80 \%$ inhibition (Table 3$)$. FIC index value showed that ocimene (0.046) was the most synergistic molecule against mature biofilm followed by cinnamaldehyde (0.061), camphene (0.062) and farnesene (0.280) (Table 3).

\section{Discussion}

Search for novel and potent antifungal agents are intensified in recent years because currently available drugs like azoles and polyenes etc., are not very promising against increasing incidences of difficult-to-treat fungal infections [7]-[10]. Plants produces structurally diverse group of molecules in response to various biotic and abiotic stresses as a defense mechanism in addition to signaling and attracting pollinators [31]. These molecules reported to exhibit excellent biological activities since they are synthesized against various biological agents (pests) [31]. Terpene the largest group of plant secondary metabolite being used for flavouring and fragrance from centuries is being exploited in recent years for their multifarious biological activities [31]. Essential oils rich in ocimene, farnesene, camphene and cinnamaldehyde reported to exhibit various biological activity including anti-Candida activity [13] [21]-[25] [31]-[33]. However no studies are available on biological activities of ocimene but recent reports suggests ocimene could be associated with antioxidant, antifungal, anti-parasitic, anticancer, antibacterial and wound healing activities of ocimene rich essential oils [13] [21]-[25]. Farnesene produced by plants in response to insect attack reported to inhibit growth of eukaryotic (like insects, parasites) as well as prokaryotic pathogens and exhibit anticancer, anti-plasmodial, hepatoprotective, antioxidant, anti-inflammatory activity [34]-[40]. Camphene a monoterpene used in flavour and fragrance, reported to inhibit sterol biosynthesis by inhibiting sterol regulatory element-binding protein (SREBP)-1c, SREBP-2, 3-hydroxy-3 methyl-glutaryl-CoA reductase (HMGCR) in eukaryotic cells [41]-[50]. Semicarbazide derivatives of camphene showed good antifungal activity against Trichophyton mentagrophytes [41]-[50]. Camphene also reported to exhibit antioxidant, antinociceptive, antibacterial, expectorant, broncholytic, antiulcer activity and also helpful in expulsion of urolithiasis [41]-[50]. Ocimene, farnesene and camphene could be inhibiting C. albicans growth by affecting membrane integrity as terpenoids are known to cause cell wall and membrane damage [14] [15] [21]-[25]. However inhibition of sterol biosynthesis could also be associated with anti-Candida activity of camphene [50]. Cinnamaldehyde was also known to inhibit growth of various microorganisms by affecting membrane integrity, energy generation and extended-spectrum beta-lactamase (ESBL) protein dependant drug resistance [17]-[19]. Curcumin is known to induce apoptosis in eukaryotic cells and also reported to inhibit planktonic and biofilm growth of C. albicans [20] [51]. Thus membrane integrity damage and apoptosis inducing activity of cinnamaldehyde and curcumin could be associated with anti-Candida activity in our study.

Anti-morphogenic activity supports membrane integrity damage (by terpenoids and cinnamaldehyde) mediated inhibition as it led to inhibition of morphogenesis through modulation of signaling pathways involved [7] [12] [14] [15] [17]-[24]. Curcumin is reported to up regulate TUP1, a negative regulator of hypahe induction [20] [51]. Membrane damage reported to affect membrane functions including signaling and transport [14] [15] [19] [22]-[24]. Morphogenesis is considered as a survival strategy of C. albicans under extreme conditions that facilitate adhesion, colonization, invasion and destruction of host tissues by evading host immune responses and confers differential response towards antifungal agents [2]-[6]. Inhibition of morphogenesis is considered as a good strategy to avoid invasive infections and biofilm formation and plant molecules tested in this study exhibited 
excellent activity against morphogenesis (Figure 2). Cinnamaldehyde and curcumin inhibited hyphae induction significantly compared to earlier reports while it is the first report of anti-morphogenic activity of camphene, farnesene and ocimene (Figure 2).

Anti-morphogenic activity of plant molecules could be contributing to biofilm inhibition as hyphae induction is the most important prerequisite for adhesion and colonization of denture as well as intravascular medical devices like catheters, heart valves, pacemakers, stents etc., in the form of biofilms [3]-[5] [27]. Hyphae specific traits like HWP1, ALS3 etc., are essential in establishing cell-cell interaction, providing necessary support and integrity to the cells in biofilms that allows survival, proliferation, intake of nutrients, efflux of metabolic wastes, evasion of host immune responses and maintaining pool of dormant persister cells [3]-[5] [27]. All the plant molecules tested inhibited biofilm formation and activity was found to be stage dependent i.e. adhesion was more susceptible followed by developing and mature biofilms (Table 2, Supplementary Figures 1(c)-1(e)). It could be due to the differential accessibility of the C. albicans cells in addition to differential expression of drug resistant traits during adhesion, development and maturation of biofilm [3]-[5] [27]. Ocimene and farnesene were most effective, inhibited adhesion completely but failed to inhibit developing and mature biofilm completely (Table 2, Supplementary Figures 1(c)-1(e)). Plant molecules could be inhibiting adhesion and developing biofilm by inhibiting hyphae induction and elongation respectively. As cells exposed to plant molecules at $0 \mathrm{~h}$ failed to induce hyphae and thus adhesion while cells exposed after adhesion (90 min), inhibited hyphae elongation (hyphal length did not increase further after addition of plant molecules) and biofilm development further supporting the mechanism of membrane integrity damage (Supplementary Figures 1(c)-1(e)). Mature biofilms were more tolerant as cells were less accessible to plant molecules and FLC (Table 2, Supplementary Figures 1(c)-1(e)).

Combination therapy found promising against various difficult to treat diseases in recent years and various plant molecules showed excellent synergistic activity with existing drugs [9]-[12] [14]-[16]. Plant molecules showed synergistic activity with antibiotics against bacterial and fungal pathogens and mechanisms of synergy was reported to be associated with enhancing penetration and bioavailability of antibiotics [12] [14] [15]. All the five plant molecules tested, exhibited excellent synergy with FLC against planktonic and biofilm growth of a recalcitrant strain of C. albicans (ATCC 10231) [28]. It indicates that plant molecules tested could find use in combination therapy against difficult-to-treat infections of C. albicans [9] [14]-[16]. It is significant as it could lower the dosage further reducing risk of side effects associated with higher dosage and prolonged use of antifungal agents [8] [9] [14]-[16]. Synergistic activity was found to be dependent on accessibility of the cells i.e. very active against planktonic growth (accessible), followed by developing biofilm (less accessible) and mature biofilm (inaccessible) [3]-[5] [27] [51].

Thus ability to cross the barriers of biofilm matrix could be associated with the differential synergistic activity of plant molecules with FLC against biofilm growth of C. albicans in addition to earlier hypothesized mechanism of membrane fluidization mediated modulation of signaling, transport and cell cycle arrest [14] [15] [23] [24].

\section{Conclusions}

Our study showed that all the five plant molecules tested exhibited excellent activity against planktonic growth and morphogenesis. Membrane destabilizing activity could be associated with anti-Candida activity as modulation of membrane functions like cell signalling reported to inhibit morphogenesis and cell cycle. Activity against biofilm formation was found to be differential and it could be due to differential accessibility of the cells in biofilm. Inhibition of hyphae induction and elongation affects adhesion and biofilm development, respectively. All the five plant molecules exhibited excellent synergy with FLC even against recalcitrant biofilms, strengthening their candidature as possible anti-Candida agents in combination therapy.

Based on our findings, we conclude that compounds tested in this study may find use in antifungal chemotherapy alone or in combination with FLC. Considering the high intake of these molecules in the form of flavouring agents in food products, toxicity concerns (at MICs) may not arise however detailed toxicity study is needed.

\section{Acknowledgements}

Authors are thankful to Prof. Dr. Pandit Vidyasagar, Honorable Vice Chancellor of our University for availing infrastructural facility and encouragement for carrying out this work. Archana Thakre had full access to all of 
the data in the study and takes responsibility for the integrity of the data and the accuracy of the data analysis.

\section{Conflict of Interest}

No conflict of interest to disclose.

\section{References}

[1] Brunke, S. and Hube, B. (2013) Two Unlike Cousins: Candida albicans and C. glabrata Infection Strategies. Cellular Microbiology, 15, 701-708. http://dx.doi.org/10.1111/cmi.12091

[2] Raja, M., Hannan, A. and Ali, K. (2010) Association of oral Candidal Carriage with Dental Caries in Children. Caries Research, 44, 272-276. http://dx.doi.org/10.1159/000314675

[3] Metwalli, K.H., Khan, S.A., Krom, B.P. and Jabra-Rizk, M.A. (2013) Streptococcus mutans, Candida albicans and the Human Mouth: A Sticky Situation. PLoS Pathog, 9, e1003616. http://dx.doi.org/10.1371/journal.ppat.1003616

[4] Ramage, G., Wickes, B.L. and Lopez-Ribot, J.L. (2007) Inhibition on Candida albicans Biofilm Formation Using Divalent Cation Chelators (EDTA). Mycopathologia, 164, 301-306. http://dx.doi.org/10.1007/s11046-007-9068-x

[5] Morgan, J. (2005) Global Trends in Candidemia: Review of Reports from 1995-2005. Current Infectious Disease Reports, 7, 429-439. http://dx.doi.org/10.1007/s11908-005-0044-7

[6] Sudbury, P.E. (2011) Growth of Candida albicans Hyphae. Nature Reviews Microbiology, 9, 737-748. http://dx.doi.org/10.1038/nrmicro2636

[7] Castelli, M.V., Butassi, E., Monteiro, M.C., Svetaz, L., Vicente, F. and Zacchino, S. (2014) Novel Antifungal Agents: A Patent Review (2011-Present). Expert Opinion on Therapeutic Patents, 24, 323-338. http://dx.doi.org/10.1517/13543776.2014.876993

[8] Huang, M. and Kao, K.C. (2012) Population Dynamics and the Evolution of Antifungal Drug Resistance in Candida albicans. FEMS Microbiology Letters, 333, 85-93. http://dx.doi.org/10.1111/j.1574-6968.2012.02587.x

[9] Johnson, M.D., Macdougall, C., Perfect, J.R., Rex, J.H. and Ostrosky-Zeichner, L. (2004) Combination Antifungal Therapy. Antimicrobial Agents and Chemotherapy, 48, 693-715. http://dx.doi.org/10.1128/AAC.48.3.693-715.2004

[10] Rodriguez, M.V., Sortino, M.A., Ivancovich, J.J., Pellegrino, J.M., Favier, L.S., et al. (2014) Detection of Synergistic Combinations of Baccharis Extracts with Terbinafine against Trichophyton rubrum with High Throughput Screening Synergy Assay ( HTSS ) Followed by 3D Graphs. Behaviour of Some of their Components. Phytomedicine, 20, 12301239. http://dx.doi.org/10.1016/j.phymed.2013.06.015

[11] Wagner, H. and Ulrich-Merzenich, G. (2009) Synergy Research: Approaching a New Generation of Phytopharmaceuticals. Phytomedicine, 16, 97-110. http://dx.doi.org/10.1016/j.phymed.2008.12.018

[12] Hemaiswarya, S., Kumar, A. and Doble, M. (2008) Synergism between Natural Products and Antibiotics against Infectious Diseases. Phytomedicine, 15, 639-652. http://dx.doi.org/10.1016/j.phymed.2008.06.008

[13] Devkatte, A.N., Zore, G.B. and Karuppayil, S.M. (2005) Potential of Plant Oils as Inhibitors of Candida albicans Growth. FEMS Yeast Research, 5, 867-873. http://dx.doi.org/10.1016/j.femsyr.2005.02.003

[14] Zore, G.B., Thakre, A.D., Jadhav, S. and Karuppayil, S.M. (2011) Terpenoids Inhibit Candida albicans Growth by Affecting Membrane Integrity and Arrest of Cell Cycle. Phytomedicine, 18, 1181-1190. http://dx.doi.org/10.1016/j.phymed.2011.03.008

[15] Zore, G.B., Thakre, A.D., Rathod, V. and Karuppayil, S.M. (2011) Evaluation of Anti-Candida Potential of Geranium Oil Constituents against Clinical Isolates of Candida albicans Differentially Sensitive to Fluconazole: Inhibition of Growth, Dimorphism and Sensitization. Mycoses, 54, e99-e109. http://dx.doi.org/10.1111/j.1439-0507.2009.01852.x

[16] Khan, M.S.A. and Ahmad, I. (2012) Antibiofilm Activity of Certain Phytocompounds and Their Synergy with Fluconazole against Candida albicans Biofilms. Journal of Antimicrobial Chemotherapy, 67, 618-621. http://dx.doi.org/10.1093/jac/dkr512

[17] Taguchi, Y., Hasumi, Y., Hayama, K., Arai, R., Nishiyama, Y. and Abe, S. (2012) Effect of Cinnamaldehyde on Hyphal Growth of C. albicans under Various Treatment Conditions. Medical Mycology Journal, 53, 199-204. http://dx.doi.org/10.3314/mmj.53.199

[18] Dhara, L. and Tripathi, A. (2013) Antimicrobial Activity of Eugenol and Cinnamaldehyde against Extended Spectrum Beta Lactamase Producing Enterobacteriaceae by in Vitro and Molecular Docking Analysis. European Journal of Integrative Medicine, 5, 527-536. http://dx.doi.org/10.1016/j.eujim.2013.08.005

[19] Gill, A.O. and Holley, R.A. (2004) Mechanisms of Bactericidal Action of Cinnamaldehyde against Listeria monocytogenes and of Eugenol against L. monocytogenes and Lactobacillus sakei. Applied and Environmental Microbiology, 70, 5750-5755. http://dx.doi.org/10.1128/AEM.70.10.5750-5755.2004 
[20] Sharma, M., Manoharlal, R., Puri, N. and Prasad, R. (2010) Antifungal Curcumin Induces Reactive Oxygen Species and Triggers an Early Apoptosis but Prevents Hyphae Development by Targeting the Global Repressor TUP1 in Candida albicans. Bioscience Reports, 30, 391-404. http://dx.doi.org/10.1042/BSR20090151

[21] Narwal, S., Rana, A.C., Tiwari, V., Gangwani, S. and Sharma, R. (2011) Review on Chemical Constituents \& Pharmacological Action of Ocimum kilimandscharicum. Indo Global Journal of Pharmaceutical Sciences, 1, $287-293$.

[22] Brennan, T.C.R., Krömer, J.O. and Nielsen, L.K. (2014) Physiological and Transcriptional Responses of Saccharomyces cerevisiae to $d$-Limonene Show Changes to the Cell Wall but Not to the Plasma Membrane. Applied and Environmental Microbiology, 79, 3590-3600.

[23] Liu, J., Zhu, Y., Du, G., Zhou, J. and Chen, J. (2013) Response of Saccharomyces cerevisiae to D-Limonene-Induced Oxidative Stress. Applied and Environmental Microbiology, 97, 6467-6475. http://dx.doi.org/10.1007/s00253-013-4931-9

[24] Trombetta, D., Castelli, F. and Sarpietro, M.G. (2005) Mechanisms of Antibacterial Activity of Three Monoterpenes. Antimicrobial Agents and Chemotherapy, 49, 2474-2478. http://dx.doi.org/10.1128/AAC.49.6.2474-2478.2005

[25] Lone, S.H., Bhat, K.A. and Bhat, H.M. (2014) Essential Oil Composition of Senecio graciliflorus DC: Comparative Analysis of Different Parts and Evaluation of Antioxidant and Cytotoxic Activities. Phytomedicine, 21, 919-925. http://dx.doi.org/10.1016/j.phymed.2014.01.012

[26] Odds, F.C. (2003) Synergy, Antagonism, and What the Chequerboard Puts between Them. Journal of Antimicrobial Chemotherapy, 52, 1. http://dx.doi.org/10.1093/jac/dkg301

[27] Hawser, S.P. and Douglas, L.J. (1994) Biofilm Formation by Candida Species on the Surface of Catheter Materials in Vitro. Infection and Immunity, 62, 915-921.

[28] Application Note 3 (2014) Use of the Candida albicans Drug Resistance (CaDR) Panel (ATCC ${ }^{\circledR}$ MP-8 ${ }^{\mathrm{TM}}$ ) in Antifungal Drug Testing. 8-10. http://www.atcc.org/ /media/PDFs/Ap\%20Notes/Application\%20note\%203\%20CADR\%20Panel\%20app.ashx

[29] Clinical and Laboratory Standards Institute (CLSI) (2012) Reference Method for Broth Dilution Antifungal Susceptibility Testing of Yeasts; Fourth International Supplement. CLSI Documents M27-S4, Clinical and Laboratory Standards Institute (CLSI), Wayne.

[30] Rand, K.H., Houck, H.J., Brown, P. and Bennewt, D. (1993) Checkerboard Method for Antibiotic Synergy. Reproducibility of the Micro Dilution Checkerboard Method for Antibiotic Synergy. Antimicrobial Agents and Chemotherapy, 37, 613-615. http://dx.doi.org/10.1128/AAC.37.3.613

[31] Gershenzon, J. and Dudareva, N. (2007) The Function of Terpene Natural Products in the Natural World. Nature Chemical Biology, 3, 408-414. http://dx.doi.org/10.1038/nchembio.2007.5

[32] Zuzarte, M., Vale-Silva, L., Goncalves, M.J., Cavaleiro, C., Vaz, S., Canhoto, J., et al. (2012) Antifungal Activity of Phenolic-Rich Lavandula multifida L. Essential Oil. European Journal of Clinical Microbiology \& Infectious Diseases, 31, 1359-1366.

[33] Singh, B.K., Tripathi, M., Chaudhari, B.P., Pandey, P.K. and Kakkar, P. (2012) Natural Terpenes Prevent Mitochondrial Dysfunction, Oxidative Stress and Release of Apoptotic Proteins during Nimesulide-Hepatotoxicity in Rats. PLoS ONE, 7, e34200. http://dx.doi.org/10.1371/journal.pone.0034200

[34] Afoulous, S., Ferhout, H., Raoelison, E.G., Valentin, A., Moukarzel, B., Couderc, F., et al. (2013) Chemical Composition and Anticancer, Antiinflammatory, Antioxidant and Antimalarial Activities of Leaves Essential Oil of Cedrelopsis grevei. Food and Chemical Toxicology, 56, 352-362. http://dx.doi.org/10.1016/j.fct.2013.02.008

[35] Mozdianfard, M., Akhbari, M. and Batooli, H. (2012) Comparative Study on the Antioxidant Activities of the Different Extracts and the Composition of the Oil Extracted by $n$-Hexane from Iranian Vitex pseudo-negundo. Natural Product Research: Formerly Natural Product Letters, 26, 2162-2167. http://dx.doi.org/10.1080/14786419.2011.643308

[36] Can, O.D., Ozkay, U.D., Kıyan, H.T. and Demirci, B. (2012) Psychopharmacological Profile of Chamomile (Matricaria recutita L.) Essential Oil in Mice. Phytomedicine, 19, 306-310. http://dx.doi.org/10.1016/j.phymed.2011.10.001

[37] Sun, Y., Qiao, H., Ling, Y., Yang, S., Rui, C., Pelosi, P., et al. (2011) New Analogues of (E)- $\beta$-Farnesene with Insecticidal Activity and Binding Affinity to Aphid Odorant-Binding Proteins. Journal of Agricultural and Food Chemistry, 59, 2456-2461. http://dx.doi.org/10.1021/jf104712c

[38] Vinholes, J., Rudnitskaya, A., Gonçalves, P., Martel, F., Coimbra, M.A. and Rocha, S.M. (2014) Hepatoprotection of Sesquiterpenoids: A Quantitative Structure-Activity Relationship (QSAR) Approach. Food Chemistry, 146, 78-84. http://dx.doi.org/10.1016/j.foodchem.2013.09.039

[39] Tariku, Y., Hymete, A., Hailu, A. and Rohloff, J. (2010) Constituents, Antileishmanial Activity and Toxicity Profile of Volatile Oil from Berries of Croton macrostachyus. Natural Product Communications, 5, 975-980.

[40] Pare, P.W. and Tumlinson, J.H. (1997) De Novo Biosynthesis of Volatiles Induced by Insect Herbivory in Cotton Plants. Plant Physiology, 114, 1161-1167. 
[41] Tiwari, M. and Kakkar, P. (2009) Plant Derived Antioxidants-Geraniol and Camphene Protect Rat Alveolar Macrophages against t-BHP Induced Oxidative Stress. Toxicology in Vitro, 23, 295-301. http://dx.doi.org/10.1016/j.tiv.2008.12.014

[42] Schafer, D. and Schafer, W. (1981) Pharmacological Studies with an Ointment Containing Menthol, Camphene and Essential Oils for Broncholytic and Secretolytic Effects. Arzneimittel-Forschung, 31, 82-86.

[43] Yamaguchi, M.U., Barbosa da Silva, A.P., Ueda-Nakamura, T., Dias Filho, B.P., Conceicao da Silva, C. and Nakamura, C.V. (2009) Effects of a Thiosemicarbazide Camphene Derivative on Trichophyton mentagrophytes. Molecules, 14, 1796-1807. http://dx.doi.org/10.3390/molecules14051796

[44] Eldon, M., Boyd, M.D. and Sheppard, P. (1970) Nutmeg Oil and Camphene as Inhaled Expectorants. Archives of Otolaryngology, 92, 372-378. http://dx.doi.org/10.1001/archotol.1970.04310040060011

[45] Magwa, M.L., Gundidza, M., Gwerua, N. and Humphrey, G. (2006) Chemical Composition and Biological Activities of Essential Oil from the Leaves of Sesuvium portulacastrum. Journal of Ethnopharmacology, 103, 85-89. http://dx.doi.org/10.1016/j.jep.2005.07.024

[46] Sharma, N. and Tripathi, A. (2008) Effects of Citrus sinensis (L.) Osbeck Epicarp Essential Oil on Growth and Morphogenesis of Aspergillus niger (L.) Van Tieghem. Microbiological Research, 163, 337-344. http://dx.doi.org/10.1016/j.micres.2006.06.009

[47] Chua, M.E., Park, J.H., Castillo, J.C. and Morales Jr., M.L. (2013) Terpene Compound Drug as Medical Expulsive Therapy for Ureterolithiasis: A Meta-Analysis. Urolithiasis, 41, 143-151. http://dx.doi.org/10.1007/s00240-012-0538-3

[48] Moro, A., Libran, C.M., Berruga, M.I., Zalacain, A. and Carmona, M. (2013) Mycotoxicogenic Fungal Inhibition by Innovative Cheese Cover with Aromatic Plants. Journal of the Science of Food and Agriculture, 93, 1112-1118. http://dx.doi.org/10.1002/jsfa.5859

[49] Baananou, S., Bouftira, I., Mahmoud, A., Boukef, K., Marongiu, B. and Boughattas, N.A. (2013) Antiulcerogenic and Antibacterial Activities of Apium graveolens Essential Oil and Extract. Natural Product Research: Formerly Natural Product Letters, 27, 1075-1083. http://dx.doi.org/10.1080/14786419.2012.717284

[50] Kim, J.H., Lee, H.J., Jeong, S.J., Lee, M.H. and Kim, S.H. (2012) Essential Oil of Pinus koraiensis Leaves Exerts Antihyperlipidemic Effects via Up-Regulation of Low-Density Lipoprotein Receptor and Inhibition of Acyl-Coenzyme A: Cholesterol Acyltransferase. Phytotherapy Research, 26, 1314-1319. http://dx.doi.org/10.1002/ptr.3734

[51] Shahzad, M., Sherry, L., Rajendran, R., Edwards, C.A., Combet, E. and Ramage, G. (2014) Utilising Polyphenols for the Clinical Management of Candida albicans Biofilms. International Journal of Antimicrobial Agents, 44, $269-273$. http://dx.doi.org/10.1016/j.ijantimicag.2014.05.017 


\section{Supplementary}

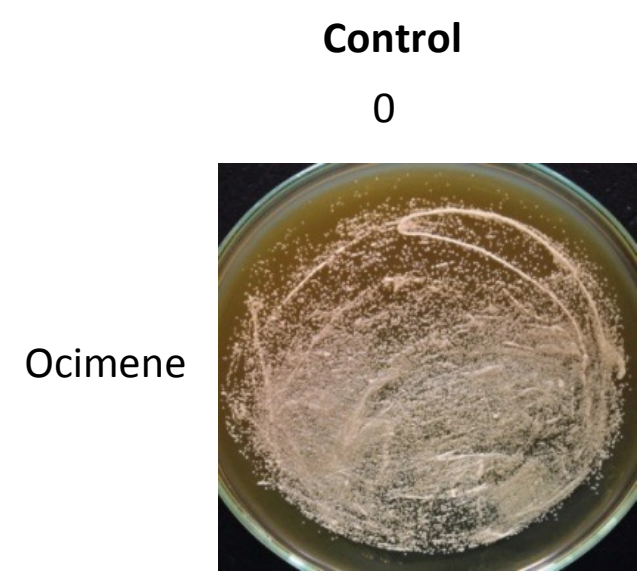

0
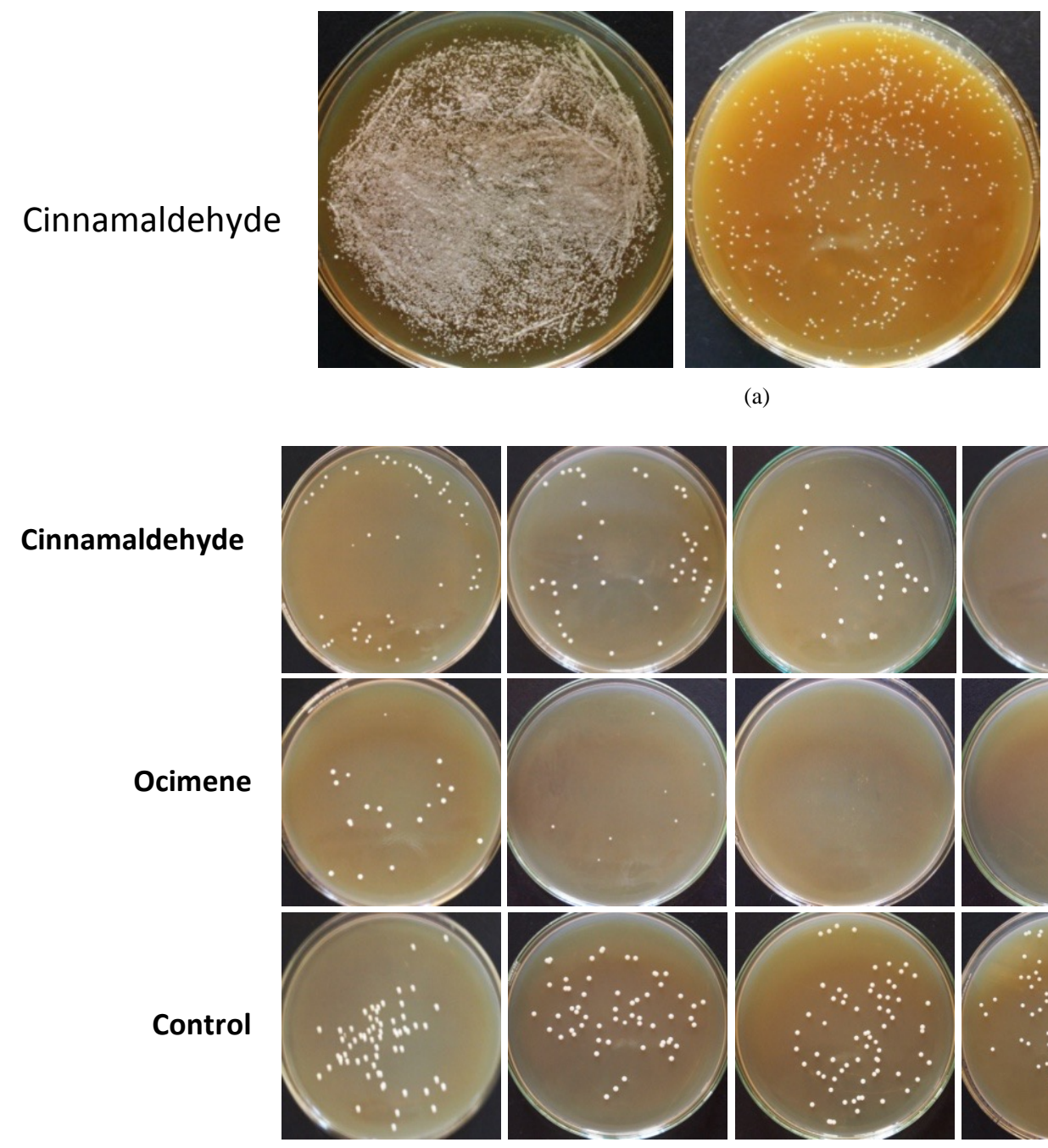

5
10

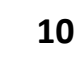

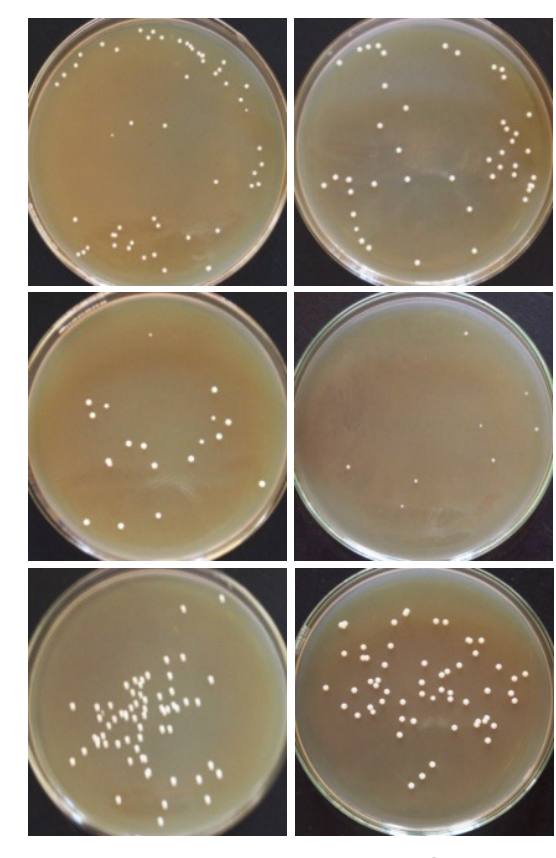

Cinnamaldehyde (a)

MIC (mM)

44.1

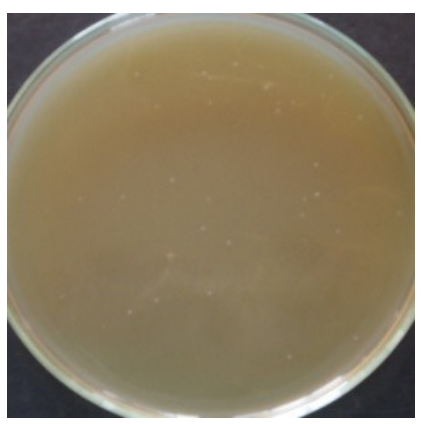

0.31
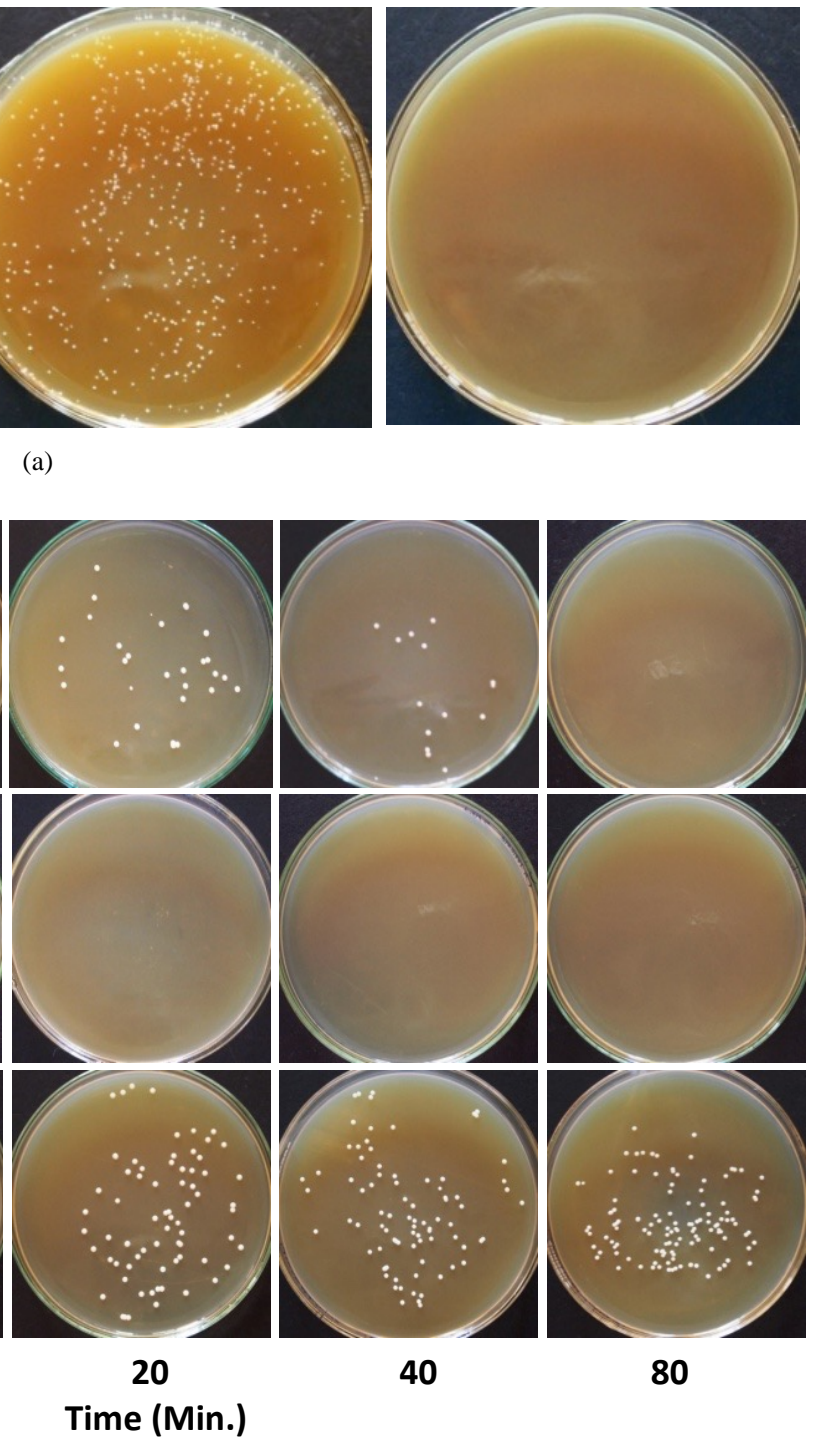

(b)

MFC (mM)

88.2

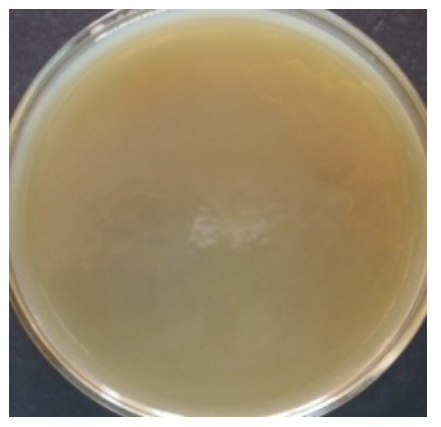

0.62 

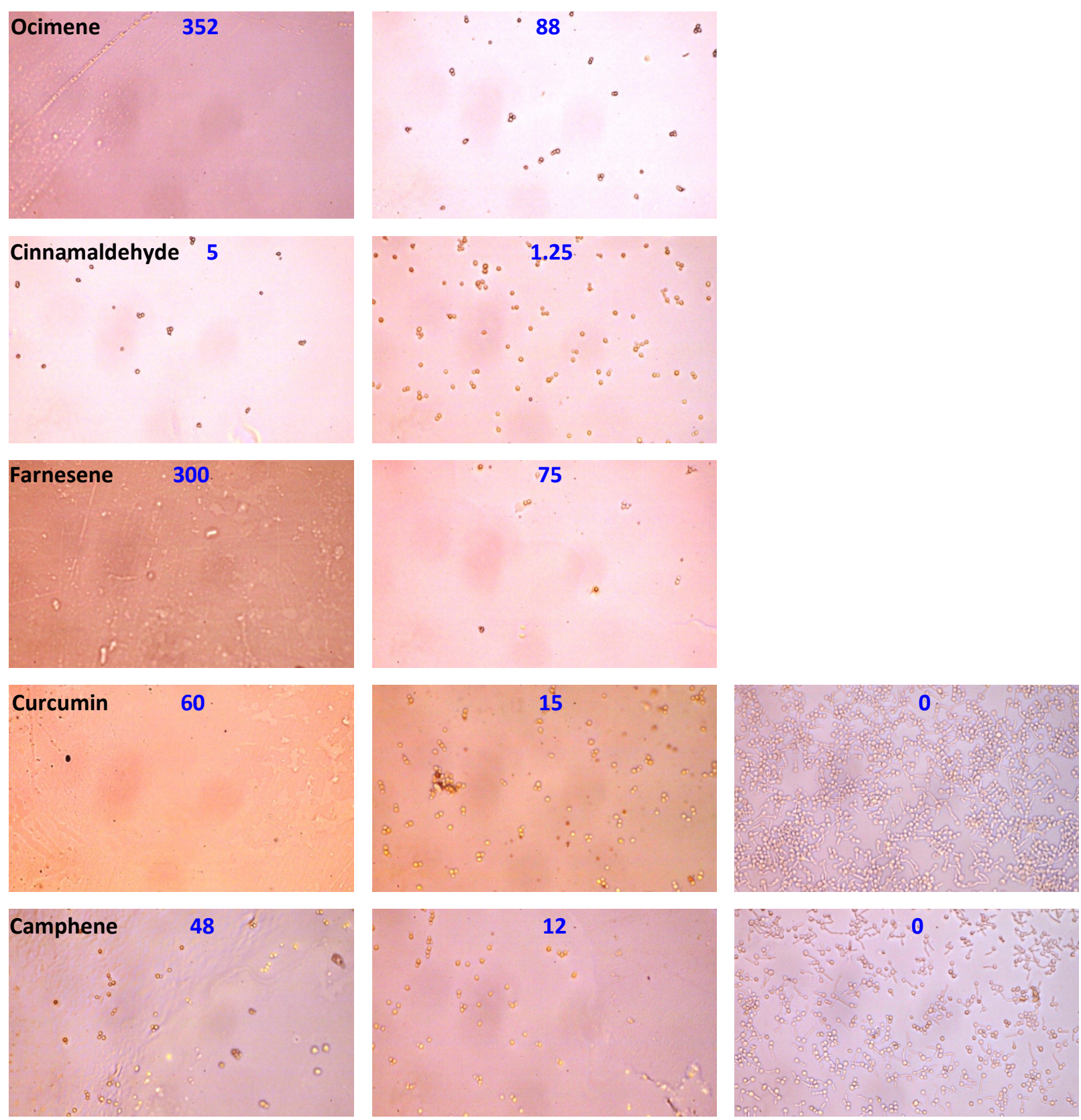

(c) 

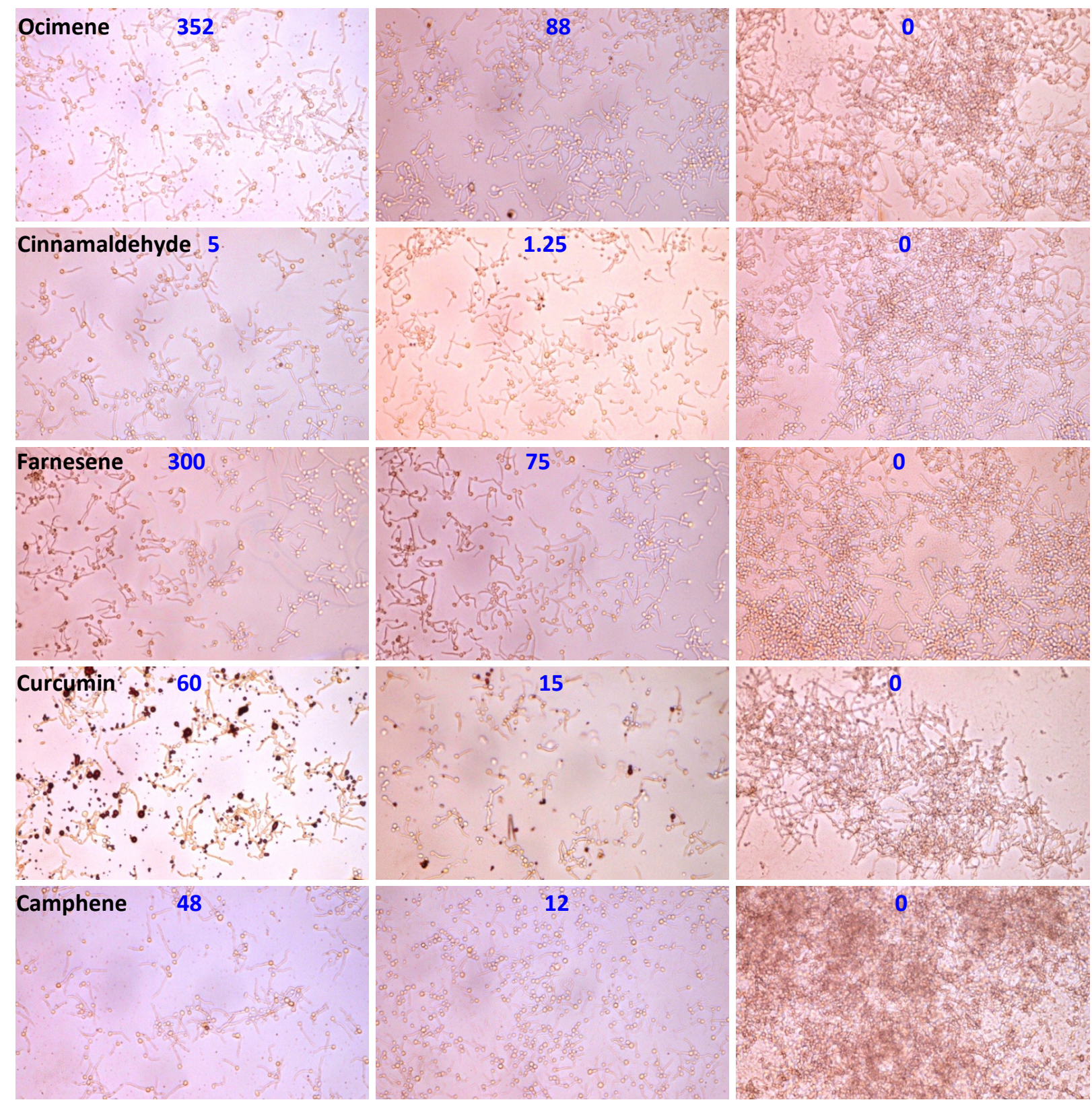

(d) 

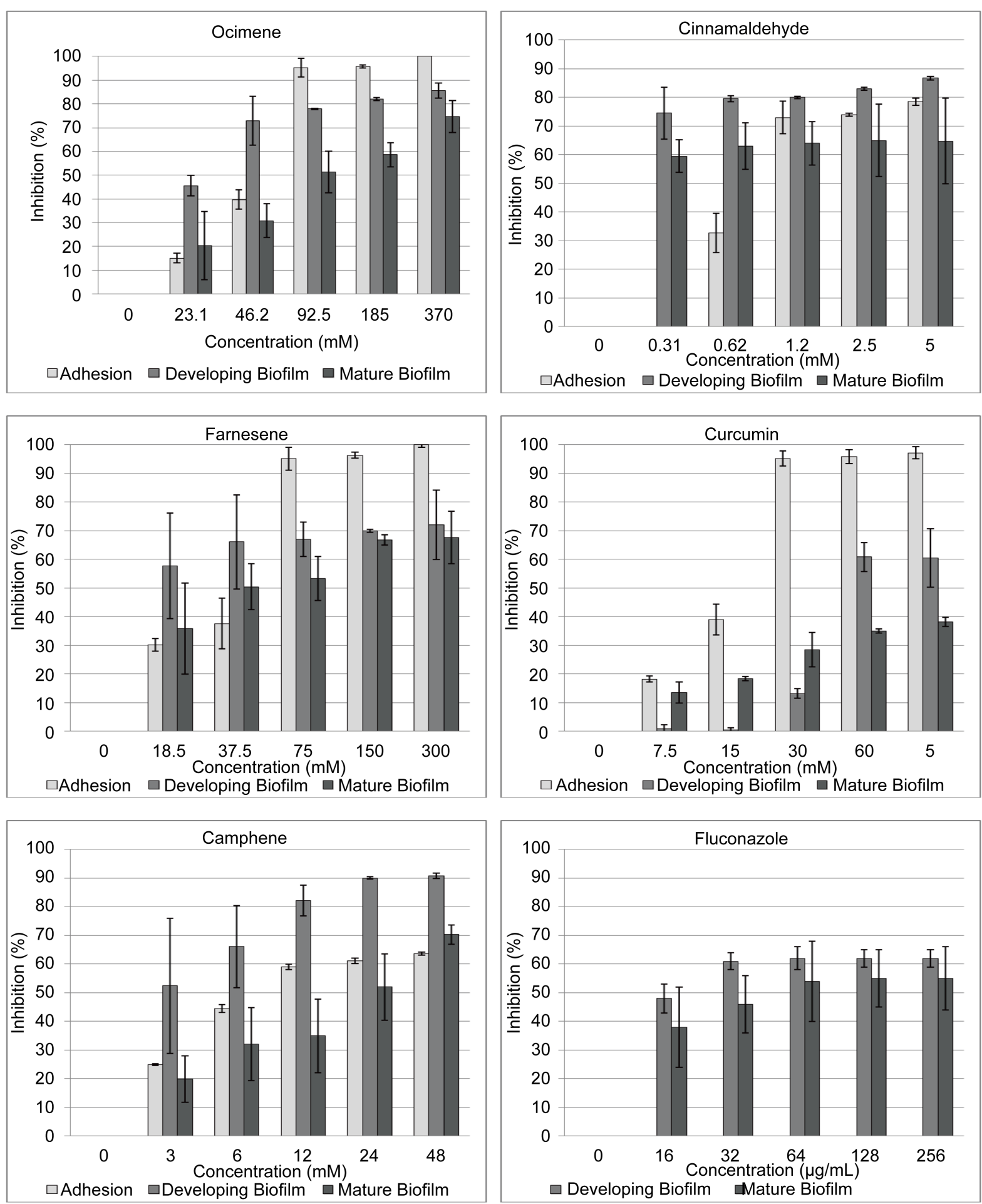

(e)

Supplementary Figure 1. (a) Determination of MFCs; (b) Time dependant Killing Candida albicans inoculums by MFCs; (c) Effect of Terpenoids (concentrations in $\mathrm{mM}$ ) on Adhesion of Candida albicans ATCC 10231. (Values indicate concentrations of plant molecule tested in mM; 0 mM represents respective controls); (d) Effect of Terpenoids (Concentrations in mM) on developing Biofilm of Candida albicans ATCC 10231. (Values indicate concentrations of plant molecule tested in mM; 0 mM represents respective controls); (e) Effect of Plant Molecules on Adhesion, Developing Biofilm and Mature Biofilm of a Fluconazole Resistant Strain of Candida albicans (ATCC 10231). 